\title{
Associated Factors with Sexual Assaults in A Gynaecology Emergency Department
}

\author{
Baquedano Mainar L*, Alvarez Sarrado L, Rodriguez Solanilla B, Sanz Arenal A and Cebolla Gil \\ Obstetrics and Gynecology Service, Miguel Servet University Maternity Hospital, Zaragoza, Spain
}

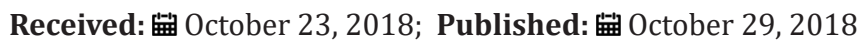

*Corresponding author: Laura Baquedano Mainar, Obstetrics and Gynecology Service, Miguel Servet University Maternity Hospital, Zaragoza, Spain

\begin{abstract}
Objective: to study associated factors with sexual assaults suffered by patients attended in the Gynaecology Emergency Department in Miguel Servet University Maternity Hospital.

Methods: descriptive cross-sectional study of sexual assaults from October 2016 to April 2018 in Miguel Servet University Maternity Hospital.

Results: 52 cases of sexual assault were attended from 50 different women. The patient profile was: young woman, with an average age of 28 years old ( $24 \%$ were minors), attacked by penetration (57.7\%), by a single assailant ( $80.8 \%)$, with no objective lesions in genitals (86.5\%) nor other parts of the body (65.4\%). 50\% of the assaults took place during the week-end and $63.5 \%$ of the victims came to the Gynaecology Emergency Department in less than 24 hours from the incident. $75 \%$ of women reported the assault to the police.

Conclusion: patients were mostly young, without secondary physical lesions and assaulted with penetration by a single assailant. An appropriate coordination between health workers, the police, and forensic experts is fundamental to handle the situation properly.
\end{abstract}

Keywords: Sexual assault; Associated factors; Epidemiology; Emergency Department; Patient profile.

\section{Introduction}

Violence against women constitutes an infringement of fundamental rights, not only affecting the victims but the whole society itself. According to a survey published in 2014 by the FRA (European Union Agency for Fundamental Rights), of 42,000 women from the 28 European Union Member States, 1 out of 10 women $(10 \%)$ has suffered any kind of sexual violence since they were 15 years old; 1 out of 20 women (5\%) has been raped after the age of 15 ; and 1 out of 5 women surveyed (20\%) had suffered indecent touching against their will. In addition, 1 out of 4 women (25\%) did not report the incident of sexual violence to the police [1]. The objective of our study consists in compiling data from patients who came to the maternity emergency room of Miguel Servet University Hospital (a tertiary-level hospital, reference in Aragón) for sexual assault and to describe the victim and assailant's characteristics as well as the context of the incident to identify possible risk factors associated.

\section{Materials and Methods}

Descriptive cross-sectional study including all women attending the Gynaecology Emergency Department of Miguel Servet
University Maternity Hospital in Zaragoza from October 2016 to April 2018. A total of 50 women were included, one of them was attended in 3 different occasions. Data was collected by the patient's hospital discharge report and electronic clinical history. Women arrived either accompanied by the UFAM (in Spanish, Family and Women Unit of the Judicial Police) or by themselves. In this last case, police were warned from the Emergency Department and came to the hospital to take testimony from the victim. Likewise, a forensic expert was informed. The testimony, as well as the sample gathering, were always taken in presence of the forensic expert together with two specialists in Gynaecology and Obstetrics.

For the data collecting, a specific worksheet was design using the IBM Statistics Process Social Sciences 22.0 for Windows application, that allowed the statistical analysis at a later stage. This database did not use personal details, guaranteeing the patient's anonymity and hence, respecting the principle of confidentiality. This study was carried out respecting the current laws and regulations including the ethical principles contained in the Declaration of Helsinki. For the descriptive analysis of our sample, arithmetic means were used for quantitative variables and percentages for categorical variables. 


\section{Results}

Table 1: Description of the characteristics of patients attended, assailant and context of incident. Data is shown as relative frequencies and percentages. Age is shown as arithmetic mean and median.

\begin{tabular}{|c|c|c|c|}
\hline & Total (\%) & & Total (\%) \\
\hline № aggressions & 52 & Known assailant & \\
\hline № women & 50 & Yes & $24(46,2 \%)$ \\
\hline Age & & No & $23(44,2 \%)$ \\
\hline Mean $[\mathrm{SD}]$ & $28,42[13,5]$ & Not specified & $5(9,6 \%)$ \\
\hline Median [P25-P75] & $26,5[17,75-37,5]$ & Number of assailants & \\
\hline Nationality & & One & $42(80,8 \%)$ \\
\hline Spanish & $29(58 \%)$ & Several & $5(9,6 \%)$ \\
\hline Other & $21(42 \%)$ & Not specified & $5(9,6 \%)$ \\
\hline Week-end & & Penetration & \\
\hline Yes & $26(50 \%)$ & Yes & $30(57,7 \%)$ \\
\hline No & $23(44,2 \%)$ & No & $5(9,6 \%)$ \\
\hline Not specified & $3(5,8 \%)$ & Not specified & $17(32,7 \%)$ \\
\hline Interval between incident and attendance & & Drug abuse & \\
\hline$<24$ horas & $33(63,5 \%)$ & No & $29(55,8 \%)$ \\
\hline $24-48$ horas & $6(11,5 \%)$ & Alcohol & $20(38,5 \%)$ \\
\hline 48-72 horas & $2(3,8 \%)$ & Cocaine & $5(9,7 \%)$ \\
\hline$>72$ horas & $8(15,4 \%)$ & Cannabis & $3(5,6 \%)$ \\
\hline No se especifica & $3(5,8 \%)$ & Speed & $1(2 \%)$ \\
\hline Place of aggression & & Physical lesions & \\
\hline Home & $29(55,7 \%)$ & Genitals & $7(13,5 \%)$ \\
\hline Outdoors & $14(27 \%)$ & Different locations & $18(34,6 \%)$ \\
\hline Not specified & $9(17,3 \%)$ & & \\
\hline \multicolumn{4}{|l|}{ Report } \\
\hline Yes & $39(75 \%)$ & & \\
\hline No & $13(25 \%)$ & & \\
\hline
\end{tabular}

SD: standard deviation.

P25-75: percentile 25-75.

During the study period, 50 women were attended for sexual assault, one of them came in 3 different occasions for the same reason. The main characteristics are exposed in Table 1. Women's average age was 28.42 years old. Nearly half of them (48\%) were under 25, and 12 (24\%) were minors. Half of the assaults occurred during the week-end. Most women attended to the Gynecology Emergency Department in the first 24 hours from the incident. $55.7 \%$ of aggressions took place in a place of residence $15.4 \%$ in the victim's house, $28.8 \%$ in the assailant's house and $11.5 \%$ in the house the victim and assailant shared). 30 women (57.7\%) referred some kind of penetration (vaginal, anal or oral). In $46.2 \%$ of cases, the assailant was someone known by the victim (partner, friend

or colleague), being in these cases the aggressor a single person. From the 23 women who reported the aggression by an unknown assailant, in 5 cases $(21.7 \%)$ there were 2 or more aggressors. A sub-analysis has been performed based on the age of the patients. Results are shown in Table 2. 44.2\% of women recognized having being under the effects of alcohol or any other drugs at the time of the assault. 20 women (38.5\%) had drank alcohol in moderatehigh quantities, 5 women $(9.7 \%)$ had used cocaine and 3 women (5.6\%) cannabis. 13 urine samples were collected for toxicological analysis. $30 \%$ of samples were positive in toxics (1 in cocaine, 1 in cannabis, 1 in cocaine and cannabis and 1 in benzodiazepines and cocaine). During the physical examination, lesions in external 
genitals (erythema and erosions) were found in 7 women (13.5\%). Neither vaginal or anal tears nor vulvar or perineal bleeding lesions were found. In 18 women (34.6\%) skin injuries were found (bruisings, grazes, erosions and ecchymosis).

Table 2: Sub-analysis of the characteristics of patients attended, assailant and context of the incident according to the age of the victim. Data is shown as relative frequencies and percentages.

\begin{tabular}{|c|c|c|}
\hline & Age 12-29 (\%) & Age 30-65 (\%) \\
\hline № aggressions & $33(63,5 \%)$ & $19(36.5 \%)$ \\
\hline \multicolumn{3}{|l|}{ Week-end } \\
\hline Yes & $17(51,5 \%)$ & $9(47.4 \%)$ \\
\hline No & $14(42,4 \%)$ & $9(47,4 \%)$ \\
\hline Not specified & $2(6.1 \%)$ & $1(5,2 \%)$ \\
\hline \multicolumn{3}{|c|}{ Place os aggression } \\
\hline Home & $16(48.5 \%)$ & $13(68,4 \%)$ \\
\hline put doors & $11(33,3 \%)$ & $3(15,8 \%)$ \\
\hline Not specified & $6(18,2 \%)$ & $3(15,8 \%)$ \\
\hline \multicolumn{3}{|l|}{ Known assailant } \\
\hline Yes & $15(45,5 \%)$ & $9(47,4 \%)$ \\
\hline No & $13(39,4 \%)$ & $8(42,1 \%)$ \\
\hline Not specified & $5(15.1 \%)$ & $2(10,5 \%)$ \\
\hline \multicolumn{3}{|c|}{ Number of assailants } \\
\hline One & $23(69.6 \%)$ & $17(89,5 \%)$ \\
\hline Several & $5(15,2 \%)$ & $0(0 \%)$ \\
\hline Not specified & $5(15,2 \%)$ & $2(10,5 \%)$ \\
\hline \multicolumn{3}{|l|}{ Report } \\
\hline Yes & $25(75,8 \%)$ & $14(73,7 \%)$ \\
\hline No & $8(24,2 \%)$ & $5(26,3 \%)$ \\
\hline \multicolumn{3}{|l|}{ Drug abuse } \\
\hline No & $18(54,6 \%)$ & $11(57,9 \%)$ \\
\hline Alcohol & $14(42,4 \%)$ & $6(31,6 \%)$ \\
\hline Cocaine & $2(6 \%)$ & $3(15,8 \%)$ \\
\hline Cannabis & $2(6 \%)$ & $0(0 \%)$ \\
\hline Speed & $0(0 \%)$ & $1(5,2 \%)$ \\
\hline
\end{tabular}

\section{Discussion}

In our study, victims of sexual assault were mostly young women (with an average age of 25 years old [2]), and the mechanism of aggression was penetration by a single assailant. The majority did not suffered objective physical lesions. In 2013, the US Department of Justice published a report collecting data on women suffering sexual violence including 146570 women. Statistics showed that $78 \%$ of sexual violence involved an offender known by the victim;
$58 \%$ of women suffered some type of physical injury during the incident; $55 \%$ of aggressions occurred at or near the victim's home; $90 \%$ of events was carried out by one single aggressor; and $64 \%$ of women had not reported the assault to the police [3]. These data are slightly far from those published by Larsen et al. in a descriptive case study carried out in Denmark. 2541 women attending the Center for Victims of Sexual Assault in Copenhagen from 2001 to 2010 were surveyed. According to this study, 70\% of the victims reported the assault to the police (figure more consistent with data in our study showing $75 \%$ of reports to the police); $44 \%$ of assaults were carried out by a perpetrator known by the victim (similar to $46 \%$ in our statistics); a physical injury was found in 53\% of victims (in our study the percentage was lower, 35\%); alcohol was involved in $60 \%$ of the cases (compared to $38 \%$ in our sample); and $57 \%$ of the assaults had occurred at a place of residence [4]. A very similar percentage was obtained in our study (56\%).

In Spain, Grau Cano et al. published in 2011 an individual cross-sectional study of sexual assault treated in the Emergency Department of a referral hospital, including 712 patients. According to this study, when the perpetrator was known by the victim, the aggression was more frequently carried out during the week, at home, and the mechanism of aggression was penetration by a single assailant. On the contrary, when the perpetrator was not known by the victim, the aggression took place more frequently in a public place and the percentage of assaults carried out by more than one assailant increased. Moreover, when the aggression took place during the week-ends, victims were mainly young women and the assailants unknown [5]. $87.5 \%$ of women included in the study reported the assault to the police. The rate of reports to the police by sexual assault victims differs significantly amongst different publications. Jones et al. in 2009, published a study where causes why victims of sexual assault decided not to report the aggression to the police were analyzed. According to this study, 25\% of women attending a hospital's Emergency Department for sexual assault decided not to report the incident. Authors concluded than the main reasons for not reporting the assault were the fear that the assailant went to jail, a prior relationship with the assailant and feeling that the police would blame the victim or be insensitive. Psychological barriers such as shame, anxiety or fear were not significantly associated with reporting the sexual assault [6]. This is the first paper in our reference population the study the patient's characteristics attended for sexual assault. The sample obtained is still small and the inclusion of more patients in our data-base is necessary to obtain definitive conclusions.

\section{Conclusion}

The patient profile of women attending the Emergency Department for sexual assault in our environment was young woman ( $24 \%$ were minors), attacked by penetration, during the week-end, by a single assailant with no objective physical lesions. An appropriate coordination between health workers, police and 
forensic experts is fundamental to manage these situations and guarantee an accurate intervention for the victims.

\section{References}

1. (2014) European Union Agency for Fundamental Rights (FRA). Violence against women: an EU-wide survey. Main results. Luxembourg: European Union publication office p. 44.

2. Ingemann-Hansen O, Sabroe S, Brink O, Knudsen M, Charles AV (2009) Characteristics of victims and assaults of sexual violence-improving inquiries and prevention. J Forensic Leg Med 16(4): 182-188.

3. Planty M, Langton L, Krebs C, Berzofsky M, Smiley-McDonald H (2013) Female victims of sexual violence, 1994-2010. US Department of Justice. Office of Justice Programs. Bureau of Justice Statistics 12: 8.
4. Larsen ML, Hilden M, Lidegaard $\emptyset ~(2015)$ Sexual assault: a descriptive study of 2500 female victims over a 10-year period. BJOG 122(4): $577-$ 584.

5. Grau-Cano J, Santiña-Vila M, Ríos-Guillermo J, Céspedes-Lacia F, MartínezGalilea B (2011) Descripción de las agresiones sexuales atendidas en el servicio de urgencias de un centro hospitalario de referencia. Gac Sanit 25(2): 166-169.

6. Jones JS, Alexander C, Wynn BN, Rossman L, Dunnuck C (2009) Why women don't report sexual assault to the police: the influence of psychosocial variables and traumatic injury. J Emerg Med 36(4): 417424.

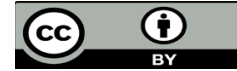

This work is licensed under Creative Commons Attribution 4.0 License

To Submit Your Article Click Here:

Submit Article

DOI: 10.32474/IGWHC.2018.03.000152 